OPEN ACCESS

Edited by:

Xiangming Zhou,

Brunel University London,

United Kingdom

Reviewed by:

Guosong Wu,

Hohai University, China

Faruk Mert,

Ankara Yıldırım Beyazıt University,

Turkey

${ }^{*}$ Correspondence:

Daniel Höche

daniel.hoeche@hzg.de

Specialty section:

This article was submitted to

Structural Materials,

a section of the journal

Frontiers in Materials

Received: 23 June 2020

Accepted: 30 March 2021

Published: 23 April 2021

Citation:

Höche D, Weber WE

Gazenbiller E, Gavras S, Hort N and Dieringa $H$ (2021) Novel Magnesium Based Materials: Are They Reliable Drone Construction Materials? A Min

Review. Front. Mater. 8:575530.

doi: 10.3389/fmats.2021.575530

\section{Novel Magnesium Based Materials: Are They Reliable Drone Construction Materials? A Mini Review}

\author{
Daniel Höche ${ }^{1,2 *}$, Wolfgang E. Weber ${ }^{3}$, Eugen Gazenbiller ${ }^{1,2}$, Sarkis Gavras ${ }^{2,4}$, \\ Norbert Hort ${ }^{2,4}$ and Hajo Dieringa ${ }^{2,5}$ \\ ${ }^{1}$ Institute of Surface Science, HELMHOLTZ-Zentrum Geesthacht, Zentrum für Material-und Küstenforschung GmbH, \\ Geesthacht, Germany, ${ }^{2}$ MaglC - Magnesium Innovation Centre, HELMHOLTZ-Zentrum Geesthacht, Zentrum für \\ Material-und Küstenforschung GmbH, Geesthacht, Germany, ${ }^{3}$ Chair of Structural Analysis, Faculty of Mechanical \\ Engineering, HELMUT-SCHMIDT-University/University of the Federal Armed Forces, Hamburg, Germany, ${ }^{4}$ Institute \\ of Metallic Biomaterials, HELMHOLTZ-Zentrum Geesthacht, Zentrum für Material-und Küstenforschung GmbH, Geesthacht, \\ Germany, ${ }^{5}$ Institute of Materials and Process Design, HELMHOLTZ-Zentrum Geesthacht, Zentrum für Material-und \\ Küstenforschung GmbH, Geesthacht, Germany
}

Novel magnesium-based materials are ideal candidates for use in future aviation vehicles because they are extremely light and can therefore significantly increase the range of these vehicles. They show very good castability, are easy to machine and can be shaped into profiles or forgings to be used as components for next generation aerial vehicle construction. In the case of a large number of identical components, high-pressure die casting of magnesium alloys is clearly superior to high-pressure die casting of aluminum alloys. This is due to the lower solubility of iron in magnesium and thus tool/casting life is significantly longer. In addition, the die filling times for magnesium high-pressure die casting are approximately 30\% shorter. This is due to the lower density: aluminum alloys are approximately 50\% heavier than magnesium alloys, which is a significant disadvantage for aluminum alloys especially in the aerospace industry. There are cost-effective novel die casting alloys, besides AZ91 or AM50/60 such as DieMag633 or MRI230D, which show very good specific strength at room and elevated temperatures. In the case of magnesium-based wrought alloys, the choice is smaller, a typical representative of these materials is AZ31, but some new alloys based on $\mathrm{Mg}-\mathrm{Zn}-\mathrm{Ca}$ are currently being developed which show improved formability. However, magnesium alloys are susceptible to environmental influences, which can be eliminated by suitable coatings. Novel corrosion protection concepts for classical aerial vehicles currently under development might suitable but may need adaption to the construction constraints or to vehicle dependent exposure scenarios. Within this mini-review a paradigm change due to utilization of new magnesium materials as drone construction material is briefly introduced and future fields of applications within nextgeneration aerial vehicles, manned or unmanned, are discussed. Possible research topics will be addressed.

\footnotetext{
Keywords: ultra-lightweight construction, hybrid design, magnesium alloy, aerial vehicle, urbane mobility
} 


\section{INTRODUCTION}

Lightweight materials such as magnesium and its alloys are of great interest for the industrial sector. Potential applications can be found in the automobile industry and in civil engineering as structural components (Dieringa and Kainer, 2013), in batteries as anode material (Deng et al., 2018; Höche et al., 2018) and in medical engineering as biocompatible, resolvable implants (Kirkland, 2012; Luthringer et al., 2014). The aspects of applying magnesium based materials in vehicle concepts have been widely discussed (Dieringa et al., 2007; Dieringa and Kainer, 2009; Dieringa and Bohlen, 2016) with the result that functionalizations of magnesium alloys are feasible (Xianhua et al., 2016). Thus, it is reasonable to think about application of novel magnesium based materials to construct additional vehicle components e.g., for a quadcopter or other next generation aerial vehicles, if they meet technical and economic constraints.

Typically, drones are classified according to weight or flight range (Weibel and Hansman, 2004; Arjomandi et al., 2006; Brooke-Holland, 2012; Dalamagkidis, 2015). Of these weight or flight range classifications, improvements to ultralight-weight drones is an ultimate goal to achieve. Presently drone materials are very often composites as sandwich panels applying fiberglass, graphite fiber or aramid based systems as skin and reinforcement materials, and foams mostly based on polymers as panel core materials (Fahlstrom and Gleason, 2012). Such systems are already established within aviation sector and just need to be applied. For example, the CityAirbus, the Lilium-Jet (Lilium, 2018) or Volocopter aiming to conquer the air taxi sector construct their vehicles with CFRP concepts. Generally lightweight vehicle constructions require a high strength to weight ratio with the ability to adapt shapes onto aero- and flight dynamical requirements. In this context, morphing materials are of great interest and might bring constructional aspects to the limit (Sun et al., 2016; Goh et al., 2017). Despite this trend there is a lot of space to use new magnesium alloys, such as DieMag633, MRI230D (Gavras et al., 2019; Tu et al., 2019), Mg-Zn-Ca based (Pan et al., 2016; You et al., 2017; Tu et al., 2019), magnesium based foams (Kucharczyk et al., 2017) or high strength AM60 + 1AlN nanocomposites (Dieringa et al., 2017; Malaki et al., 2019). Particularly with regards to manned aerial vehicles (MAV's) or even air-taxis which might become very expensive and not environmental benign if they are conventionally designed. The application of magnesium in recent aerial vehicles is a first step. For example, the commercially available DJI Inspire 2 unmanned aerial vehicle (UAV), has an AZ91 housing. The DJI Mavic Air applies brackets based on AZ91. The Phantom 4 Pro V2.0 quadcopter applies a titanium magnesium hybrid structure to achieve maximal rigidity of the airframe for excellent maneuverability ${ }^{1}$. Obviously, based on this existing experience, there is a lot of potential in conceptional design approaches using magnesium materials. Possibilities going beyond this need to be further explored.

\footnotetext{
${ }^{1}$ www.dji.com
}

\section{AERIAL VEHICLE COMPONENTS}

Design of unmanned aerial vehicles and manned aerial vehicles follow the well-established construction criteria of aircraft industry. However, this does not mean that there is no space for innovation and novel thinking. Considering the price developments (Q4/2020 at 2.55-2.70 \$/kg Source: Platts Metals Week) but also enhanced manufacturing capabilities $\mathrm{Mg}$ based components might replace vehicle components and attachments (e.g., camera housings) but also on structural level.

The structure of a typical UAV consists of basic subsystems. All those components typically do not mainly differ in their function from conventional aircraft concepts but might be adapted. The most important are listed:

- The fuselage including stringers, the skin (coated), longerons (longitudinal structural members reinforcing the skin), and some bulkheads can be made from many lightweight engineering materials.

This can be impregnated fabrics, standard AA2024 structures or many other composites (CFRP, GLARE, etc.). Components for the fuselage can be made of magnesium alloys. These are, for example, sheets for the outer skin made of AZ31 or aluminum-free ZE10. The latter shows excellent forming properties and a reduced texture. Frames and cross members can be made of AM60 by high-pressure die casting. Any further fairings (and filets) can still be made of $\mathrm{Al}$ alloys or respective foils.

- The wings including the spars (mono and multi), ribs, stiffeners, and the skin in 2, 3, or 4 rotor systems (sheathed and unsheathed) are structural parts as well and critical loads are transferred to the fuselage by a topological designed beam or truss structure. Materials in use must be light but also stiff and limit vibrations. However, using current lightweight materials such as CFRP leads to structures being more flexible than desired. Thus, additional effort is necessary to limit the deformationsone example for that are truss braced wings (see e.g., Scott et al., 2016). Instead, extruded profiles of wrought magnesium alloys could be used here for the load-bearing structures; they show yield strengths of up to $300 \mathrm{MPa}$. Cast components for wing and spar construction made of AZ91 or AM60 could be used as ultralight structural components here as well.

- The tails (horizontal and vertical) very often are made of carbon- or glass fiber materials applying resins, wax and hardeners with foam cores.

- The rotor blades are mostly made of composite materials involving impregnated fabrics. Especially for UAV's which are used for civil applications in urban areas, an outer ring housing the rotor blades is necessary in order to prevent people and animals from accidental collisions and to reduce noise. This ring might be made of magnesium or magnesium alloys because this material may better withstand collisions with both the built environment and moving objects such as other UAV's. Additionally, the damping properties of such Mg based systems are excellent. 
- The engine/powertrain group consisting of for example pylons, inlet, supports, etc. does not follow the classical turbine design with Ti- or Ni based alloys. For UAV's like quadcopters electrical engines depending on battery power are required, where it should be mentioned that battery mass is a problem. Casings or heads of piston engines are often made of cast aluminum but might be replaced by Mg based materials. Ti alloys or steels are other options if the situation (temperature, etc.) requires countermeasures. Magnesium alloys for higher temperatures are available, as well, although they are often more costly (AE-series, DieMag-series, AJ-series) (Gavras et al., 2019).

- The landing gear (and if required, its bay door) can also be part of the structure especially for MAV's. It has to take up high loads and can already be made of carbon composites or simply AISI $300 \mathrm{M}$ steels.

- It should be noted that the dies for applying the forming processes mentioned above may also be made from ultrahigh performance concrete (UHPC) (see e.g., Kleiner et al., 2008), which may lead to economic gains. This holds especially for low and medium contoured part shapes. For producing parts with small radii, the UHPC dies should be additionally confined or reinforced (see also Kleiner et al., 2008).

\section{DRONE CONSTRUCTION MATERIAL REQUIREMENTS}

Material selection especially for aerospace vehicles has been introduced by Arnold et al. (2012) based on Ashby (2010). The structure and its materials have to ensure the functionality of the drone. They have to keep the aerodynamics of the UAV and carry the occurring loads at any time. Thus, structural components are constructed following the lightweight design rules (e.g., high Youngs modulus/density ratio E/ $\rho$, etc.; Arnold et al., 2012) as shown in Figure 1, whereas safe design in c) has special emphasis for manned vehicles. Here the most common material is aluminum, followed by composite materials, such as glass/epoxy and carbon fiber. Surprisingly, magnesium based materials such as magnesium based metal matrix nanocomposites (MMNC's) are yet not in use despite their very good potential. Some of these Mg-MMNC's show excellent properties caused by only small additions of ceramic nanoparticles. The great advantage of these materials is that the nanoparticles not only increase mechanical strength (by grain refinement or Orowan strengthening), but also increase ductility (Dieringa, 2011; Dieringa et al., 2017).

The structural members are designed to carry the flight loads or to handle stress without failure. In designing the structure, the entirety of the wing and fuselage must be considered in relation to the physical characteristics of the material of which it is made. Every part of the structure is engineered to carry the load which is applied on it. The structural designer has to determine flight loads (including bird strikes) and other loads, calculate stresses, and design the structural elements such as to allow the UAV components to perform their aerodynamic functions and durability requirements efficiently. This goal will be considered simultaneously with the objective of the lowest structural weight.

The entire airframe and its components are joined by rivets, bolts, screws, and other fasteners. Welding, adhesives, and special bonding techniques are also employed. In order to enhance the delamination toughness of e.g., CFRP laminates, techniques such as z-pinning are investigated (cf. Mouritz, 2007). Additionally, composite materials with enhanced delamination toughness such as GLARE are of scientific interest (see Rittmeier et al., 2018). The most common design of UAV structure is semi- monocoque (single shell) which implies that the respective skin is stressed and thus needs to be reinforced.

Structural parts of UAV's are subjected to: (1) tension, (2) compression, (3) torsion, (4) shear, and (5) bending. Typically, a single member of the structure is often subjected to a combination of the resulting stresses. It is worth mentioning that the UAV is subjected to time-harmonic loads (i.e., due to vibrations induced by the engine) and impact loads (e.g., during the landing phase, due to bird strikes or impacts such as the Hudson River landing in 2009). Additionally, fluttering as well as limit-cycle oscillations due to wind loads is a major issue. Hence, the design principles known from e.g., aeronautical applications or wind power plants are a good starting point when designing UAV's. A major issue in designing lightweightstructures from composite materials is that these structures tend to delaminate. Although there are substantial contributions to prevent structural elements from delamination, this problem is not yet solved. Promising approaches to increase delamination toughness can be found in the literature (e.g., Mouritz, 2007; Rittmeier et al., 2018). However, by suggesting magnesium based construction materials for e.g., quadcopter drones, the authors believe that the potential problem of delamination can be circumvented. This advantage holds for the drone's skin and bulkhead, which are also subjected to lateral loads. Structural members such as frames and longerons are mainly loaded longitudinally and consequently can be treated as rods in most cases (cf., Rothert and Gensichen, 1987). Using lightweight configurations made of composite materials mentioned above has another effect: the respective structures are getting more flexible. Thus, scientific effort is necessary in order to reduce the resulting deformations. For example, this led to the development of the so-called truss braced wing (see Scott et al., 2016). Again, the authors of the current contribution believe that the rigidity of structural members made of magnesium or magnesium alloys is sufficient to ensure moderate deformations and might improve acoustic emission profiles. Concerns about corrosion issues are not appropriate due to the existence of novel corrosion protection concepts (Lamaka et al., 2016; Dieringa et al., 2018) and the expected uncritical corrosive in-service exposure conditions.

Besides these mechanical and design aspects, the ecological footprint (Ehrenberger, 2020) and the social acceptance of the materials used in drone design is also of interest. Many contributions show the positive effect on fuel/energy consumption when using CFRP for MAV's (see Timmis et al., 2015). The authors expect that similar conclusions hold for UAV's and other lightweight materials such as magnesium or 

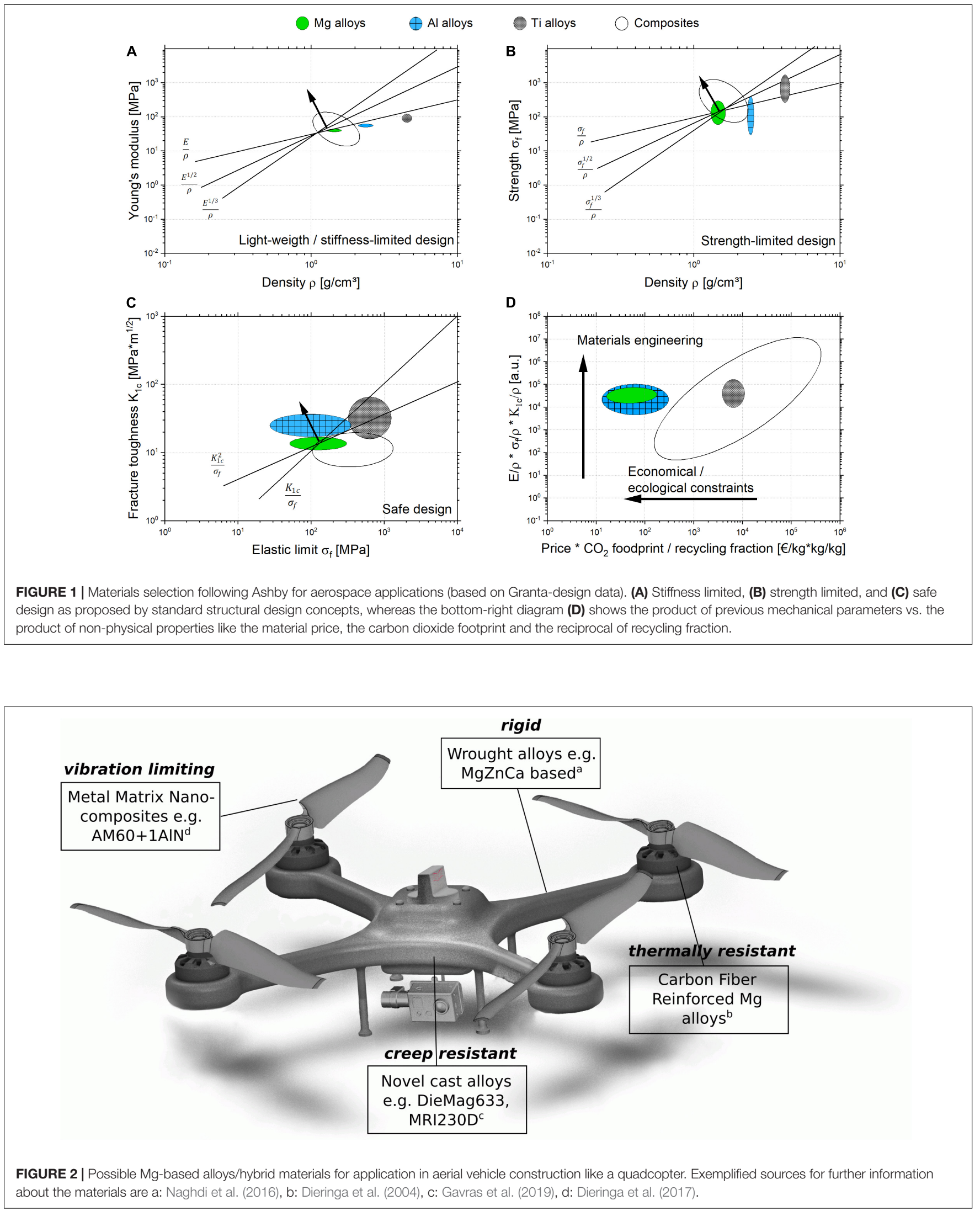
magnesium alloys. However, recycling of lightweight materials such as CFRP is challenging (Dong et al., 2018). In comparison, recycling of magnesium and magnesium alloys is quite wellunderstood. Additionally, magnesium and magnesium alloys can be separated easily from the other materials which is not the case for carbon in CFRP. Thus, from an ecological but also from an economical point of view the use of magnesium and magnesium alloys seems to be promising since the price and $\mathrm{CO}_{2}$ fingerprint are on the same level as aluminum. In a life cycle assessment study (Ehrenberger et al., 2013; Ehrenberger, 2020), it was shown that magnesium, which is primarily produced by electrolysis, has a better carbon footprint than aluminum from the production stage. Over the service life of a component, this advantage increases continuously due to its lower weight. In a comparison of aircraft components made of magnesium or aluminum, the slightly higher greenhouse gas emissions caused by the production of magnesium are compensated for after only a few flights by the fuel savings during flight.

The utilization of $\mathrm{Mg}$ based materials generally launches a fire risk discussion. A dedicated study on flammability of the material within aircraft fire tests (Marker, 2013) indicates that for example the behavior of the Mg alloy E21 does not significantly differ to aluminum alloys. Nowadays the SAE standard AS8049D paves the way toward utilization of novel $\mathrm{Mg}$ based materials (Czerwinski, 2014) at commercial cabin interiors.

\section{THE MAGNESIUM BASED URBANE AVIATION VEHICLE-DESIGN}

The use of magnesium in the aircraft industry has been an important topic since the beginning of aircraft construction. Even before the Second World War, a large number of magnesium parts were used in aircraft construction, including propellers and sheet metal for the outer skin (Reed, 1925; Beck, 1939; Hallion, 2017). During the Second World War, however, a great amount of magnesium was used to build aircrafts in Germany. Both the Messerschmidt Bf 110 and the Junkers Ju 88 used both die-cast and forged magnesium parts (small bell cranks, engine cowl flaps, large dive brake forgings) (DOW, 1941). The first all-magnesium aircraft was described in 1954 (American Aviation, 1955). The F-80C was characterized by a simpler construction of the wings, because considerably fewer components were needed, the number was reduced from 1,644 to only 508, which corresponds to a decrease of $69 \%$. The lighter construction led to an increase of the maximum speed by $5 \mathrm{mph}$. After the war, the United States built the Convair B-36 bomber, an aircraft that was made of $10 \%$ magnesium (Jenkins, 2001) large parts of the outer skin and the control parts were made of magnesium alloys. In 1950 the Sikorsky S-56 Helicopter from Westland Aircraft Ltd., applied $115 \mathrm{~kg}$ magnesium. Furthermore, in the Sovjet Union in 1963 the TU-134 from Tupolev already had 1,325 parts made of $\mathrm{Mg}$ (Ostrowsky and Henn, 2007).

The operating flight loads limits on a UAV are usually presented in the form of a V-n diagram (airspeed and load variation diagram). Structural designers selecting $\mathrm{Mg}$ based materials will construct this diagram with the cooperation of the flight dynamics group. The diagram will determine the failure areas, and area of structural damage/failure. The UAV should not be flown out of the flight envelope, since it is not safe for the structures. The UAV structural design is out of scope of this mini-review. Detailed information can be found elsewhere (Megson, 2016).

Figure 2 shows the principles and an idea to design a hypothetical quadcopter mainly based on Mg-materials. The different requirements for the respective construction parts can be fulfilled by the materials in the boxes. They are:

- Rigid-such as MgZnCa wrought alloys with $306 \mathrm{MPa}$ YS and $11 \%$ elongation (You et al., 2017).

- Vibration limiting-AM60 based nano composites with high ductility of $15.4 \%$ at RT (Dieringa et al., 2017).

- Creep resistant-such as novel DieMag alloys without rare-earth elements showing better creep resistance compared to commercial alloys and better high temperature yield strength than even aluminum alloy A380 (Gavras et al., 2019).

- High strength and thermally resistant-such as carbon fiber reinforced $\mathrm{Mg}$ MMCs up to $300^{\circ} \mathrm{C}$ (Dieringa et al., 2004).

Considering production and design aspects, it becomes obvious that besides efficient manufacturing- and surface technologies (computational based), topological design but also efficient joining technologies for Mg based parts are key enablers for this technology. It will require a concerted research effort and might also be a future market for additive manufactured parts made out of Magnesium.

\section{CONCLUSION}

Magnesium based materials can become an essential part of design concepts of UAV's, especially if flight maneuvers require high rigidity and noise pollution become critical decision criteria. Also crash-worthiness is an aspect where magnesium has benefits. The authors are convinced that the economic advantages of using magnesium based materials in drone construction may be further increased if promising techniques such as e.g., performing sheet metal hydroforming by means of UHPC dies are applied. As compared to CFRP and related composite materials, magnesium based materials can be easier separated and recycled once the UAV's reached the end of its service-life.

With respect to the title of this contribution and based on the precedent sections the authors thus are convinced that: Magnesium is-A drone construction material!

\section{AUTHOR CONTRIBUTIONS}

DH wrote the main part of the manuscript. EG performed the visualization. HD and SG contributed to the historical aspects. 
WW and $\mathrm{NH}$ contributed to the mechanical and historical aspects. All authors contributed to the manuscript revision, read and approved the submitted version.

\section{REFERENCES}

American Aviation (1955). American Aviation. 14, 58-60.

Arjomandi, M., Agostino, S., Mammone, M., Nelson, M., and Zhou, T. (2006). Classification of Unmanned Aerial Vehicles. Report for Mechanical Engineering class. Adelaide: University of Adelaide.

Arnold, S. M., Cebon, D., and Ashby, M. (2012). Materials Selection for Aerospace Systems. Tech. Rep. 2012-217411, NASA/TM. Washington, D.C: NASA.

Ashby, M. F. (2010). Materials Selection in Mechanical Design. Oxford: Butterworth-Heinemann.

Beck, A. (1939). Magnesium Und Seine Legierungen (in German), 2 Edn. Berlin: Springer.

Brooke-Holland, L. (2012). Unmanned Aerial Vehicles (drones): an Introduction. London: House of Commons Library.

Czerwinski, F. (2014). Overcoming barriers. Adv. Mat. Proc. 5, 28-31.

Dalamagkidis, K. (2015). "Classification of UAVs," in Handbook of Unmanned Aerial Vehicles, eds K. P. Valavanis and G. J. Vachtsevanos (Berlin: Springer), 83-91. doi: 10.1007/978-90-481-9707-1_94

Deng, M., Höche, D., Lamaka, S. V., Snihirova, D., and Zheludkevich, M. L. (2018). Mg-Ca binary alloys as anodes for primary Mg-air batteries. J. Power Sourc. 396, 109-118. doi: 10.1016/j.jpowsour.2018.05.090

Dieringa, H. (2011). Properties of magnesium alloys reinforced with nanoparticles and carbon nanotubes: a review. J. Mater. Sci. 46, 289-306. doi: 10.1007/ s10853-010-5010-6

Dieringa, H., and Bohlen, J. (2016). Magnesiumlegierungen im Leichtbau. Nachhaltige Konstruktion 10, 24-25.

Dieringa, H., and Kainer, K. (2009). Technologische Eigenschaften und Potential von Magnesium-legierungen (in German). Gießerei-Rundschau 56, 114-119.

Dieringa, H., and Kainer, K. U. (2013). Die Leichtbauwerkstoffe für den Fahrzeugbau (in German). Wiesbaden: Springer Fachmedien Wiesbaden, 199-442.

Dieringa, H., Bohlen, J., Hort, N., Letzig, D., and Kainer, K. U. (2007). “Advances in manufacturing processes for Magnesium alloys," in Magnesium Technology 2007 (TMS), eds R. S. Beals, A. A. Luo, N. R. Neelameggham, and M. O. Pekguleryuz (TMS The Minerals, Metals and Materials Society), 3-8.

Dieringa, H., Hort, N., and Kainer, K.-U. (2004). Magnesium based MMCss reinforced with C-fibers. Adv. Tehnol. Mater. Mater. Process. J. 6, 136-141.

Dieringa, H., Hort, N., Letzig, D., Bohlen, J., Höche, D., Blawert, C., et al. (2018). "Mg Alloys: Challenges and Achievements in Controlling Performance, and Future Application Perspectives," in Magnesium Technology 2018. TMS 2018. The Minerals, Metals \& Materials Series, eds D. Orlov, V. Joshi, K. Solanki, and N. Neelameggham (Cham: Springer).

Dieringa, H., Katsarou, L., Buzolin, R., Szakacs, G., Horstmann, M., Wolff, M., et al. (2017). Ultrasound assisted casting of an AM60 based metal matrix nanocomposite, its properties, and recyclability. Metals 7:388. doi: 10.3390/ met7100388

Dong, P. A. V., Azzaro-Pantel, C., and Cadene, A.-L. (2018). Economic and environmental assessment of recovery and disposal pathways for cfrp waste management. Resour. Conserv. Recycl. 133, 63-75. doi: 10.1016/j.resconrec. 2018.01.024

DOW (1941). Application of Magnesium Alloys on the Junckers ju-88 Bomber. The DOW chemical report. Midland, MI: The DOW Chemical Company, 11373.

Ehrenberger, S. (2020). Carbon Footprint of Magnesium Production and its Use in Transport Applications, Update of Life Cycle Assessment of Magnesium Components in Vehicle Construction. Available online at: https:/elib.dlr.de/ 140926/1/2020-10-30_IMA_LCA-Study_Report_Update.pdf (accessed March $8,2021)$.

Ehrenberger, S., Dieringa, H., and Fridrich, H. (2013). Life Cycle Assessment of Magnesium Components in Vehicle Construction. Available online at: https://elib.dlr.de/87332/1/2013-12_IMA_LCA-Study_Report_Part-I-and-II_ incl-summary.pdf (accessed June 22, 2020).

Fahlstrom, P., and Gleason, T. (2012). Introduction to UAV systems. Hoboken, NJ: John Wiley \& Sons.

Gavras, S., Zhu, S., Easton, M. A., Gibson, M. A., and Dieringa, H. (2019). Compressive creep behavior of high-pressure die-cast aluminum-containing

\section{ACKNOWLEDGMENTS}

This article is a personal acknowledgement to K. U. Kainer.

magnesium alloys developed for elevated temperature applications. Front. Mater. 6:262. doi: 10.3389/fmats.2019.00262

Goh, G., Agarwala, S., Goh, G., Dikshit, V., Sing, S. L., and Yeong, W. Y. (2017). Additive manufacturing in unmanned aerial vehicles (uavs): challenges and potential. Aerosp. Sci. Technol. 63, 140-151. doi: 10.1016/j.ast.2016.12.019

Hallion, R. P. (2017). "Germany and the invention of the all-metal cantilever airplane, 1915-1925: a historical review," in Proceedings of the 55th AIAA Aerospace Sciences Meeting, (Reston, VA: AIAA).

Höche, D., Lamaka, S. V., Vaghefinazari, B., Braun, T., Petrauskas, R. P., Fichtner, M., et al. (2018). Performance boost for primary magnesium cells using iron complexing agents as electrolyte additives. Sci. Rep. 8:7578.

Jenkins, D. R. (2001). Magnesium Overcast: The Story of the Convair B-36. Thurgoona: Specialty Press.

Kirkland, N. T. (2012). Magnesium biomaterials: past, present and future. Corros. Eng. Sci. Technol. 47, 322-328. doi: 10.1179/1743278212y.0000000034

Kleiner, M., Curbach, M., Tekkaya, A. E., Ritter, R., Speck, K., and Trompeter, M. (2008). Development of ultra-high performance concrete dies for sheet metal hydroforming. Prod. Eng. 2, 201-208. doi: 10.1007/s11740-0080099-z

Kucharczyk, A., Naplocha, K., Kaczmar, J. W., Dieringa, H., and Kainer, K. U. (2017). Current Status and Recent Developments in Porous Magnesium Fabrication. Adv. Eng. Mater. 20:1700562. doi: 10.1002/adem.201700562

Lamaka, S. V., Höche, D., Petrauskas, R. P., Blawert, C., and Zheludkevich, M. L. (2016). A new concept for corrosion inhibition of magnesium: suppression of iron re-deposition. Electrochem. Commun. 62, 5-8. doi: 10.1016/j.elecom.2015. 10.023

Lilium (2018). Simplicity was Our Most Complicated Goal. Lilium-Technology. Available online at: https://lilium.com/technology/ (accessed June 22, 2020).

Luthringer, B. J., Feyerabend, F., and Willumeit-Romer, R. (2014). “'Magnesiumbased implants: a mini-review. Magnes. Res. 27, 142-154. doi: 10.1684/mrh. 2015.0375

Malaki, M., Xu, W., Kasar, A. K., Menezes, P. L., Dieringa, H., Varma, R. S., et al. (2019). Advanced metal matrix nanocomposites. Metals 9:330. doi: 10.3390/ met9030330

Marker, T. (2013). Evaluating the Flammability of Various Magnesium Alloys During Laboratory-and Full-Scale Aircraft Fire Test. New Jersey, NY: US Department of Transportation.

Megson, T. H. G. (2016). Aircraft Structures for Engineering Students. Oxford: Butterworth-Heinemann.

Mouritz, P. A. (2007). Review of z-pinned composite laminates. Compos. Part A Appl. Sci. Manuf. 38, 2383-2397. doi: 10.1016/j.compositesa.2007. 08.016

Naghdi, F., Kang, J., and Kim, H. (2016). Microstructure and high-temperature mechanical properties of the mg- $4 \mathrm{zn}-0.5 \mathrm{ca}$ alloy in the as-cast and aged conditions. Mater. Sci. Eng. A 649, 441-448. doi: 10.1016/j.msea.2015. 10.011

Ostrowsky, I., and Henn, Y. (2007). "Present state and future of magnesium application in aerospace industry," in Proceeding of the International Conference "New Challenges in Aeronautics", (India: ASTEC).

Pan, H., Ren, Y., Fu, H., Zhao, H., Wang, L., Meng, X., et al. (2016). Recent developments in rare-earth free wrought magnesium alloys having high strength: a review. J. Alloys Compd. 663, 321-331. doi: 10.1016/j.jallcom.2015. 12.057

Reed, S. A. (1925). Aeronautical Propeller. US Patent, No. 1,542,412.

Rittmeier, L., Losch, T., Sinapius, M., and Lammering, R. (2018). Investigation on the influence of material interfaces and impedance changes on the propagation of guided waves in laminated steel layers. Procedia Manuf. 24, 196-202. doi: 10.1016/j.promfg.2018.06.039

Rothert, H., and Gensichen, V. (1987). Nichtlineare Stabstatik (in German). Berlin: Springer.

Scott, R. C., Bartels, R. E., Funk, C. J., Allen, T. J., Sexton, B. W., Dykman, J. R., et al. (2016). Aeroservoelastic test of the subsonic ultra-green aircraft research truss-braced wing model. J. Guid. Control Dyn. 39, 1820-1833. doi: 10.2514/1. g000265 
Sun, J., Guan, Q., Liu, Y., and Leng, J. (2016). Morphing aircraft based on smart materials and structures: a state-of-the-art review. J. Intell. Mater. Syst. Struct. 27, 2289-2312. doi: 10.1177/1045389x16629569

Timmis, A. J., Hodzic, A., Koh, L., Bonner, M., Soutis, C., Schafer, A. W., et al. (2015). Environmental * impact assessment of aviation emission reduction through the implementation of composite materials. Int. J. Life Cycle Assess. 20, 233-243. doi: 10.1007/s11367-014-0824-0

Tu, T., Chen, X.-H., Chen, J., Zhao, C.-Y., and Pan, F.-S. (2019). A high-ductility Mg-Zn-Ca magnesium alloy. Acta Metall. Sin. 32, 23-30.

Weibel, R., and Hansman, R. J. (2004). "Safety considerations for operation of different classes of UAVs in the nas," in Proceedings of the AIAA 4th Aviation Technology, Integration and Operations (ATIO) Forum (Reston, VA: AIAA).

Xianhua, C., Yuxiao, G., and Fusheng, P. (2016). Research progress in magnesium alloys as functional materials. Rare Metal Mater. Eng. 45, 2269-2274. doi: 10.1016/s1875-5372(17)30015-2
You, S., Huang, Y., Kainer, K. U., and Hort, N. (2017). Recent research and developments on wrought magnesium alloys. J. Magnes. Alloys 5, 239-253. doi: 10.1016/j.jma.2017.09.001

Conflict of Interest: The authors declare that the research was conducted in the absence of any commercial or financial relationships that could be construed as a potential conflict of interest.

Copyright (c) 2021 Höche, Weber, Gazenbiller, Gavras, Hort and Dieringa. This is an open-access article distributed under the terms of the Creative Commons Attribution License (CC BY). The use, distribution or reproduction in other forums is permitted, provided the original author(s) and the copyright owner(s) are credited and that the original publication in this journal is cited, in accordance with accepted academic practice. No use, distribution or reproduction is permitted which does not comply with these terms. 